\title{
Two Heuristic PID Tuning for a 4-DOF Robot Arm Control
}

\author{
M. F. M. Ariffin, R. L. A. Shauri, M. I. Roslan, W. M. L. W. Zainudin, M. A. Rosli
}

\begin{abstract}
This paper discusses the development of closed-loop position control for the joint motor of a 4-DOF robot arm. In developing a practical robot, types of input and control algorithm are important elements in the control system. The objectives of this paper are to select an input type that could produce smooth arm's motion and to apply PID control for the joints. Step and parabolic inputs have been tested as reference trajectory where the former used step signal as the constant value of motor angle while the latter requires calculation using spline interpolation method based on initial and end points of each joint motion given by user. From the latter, a parabolic curve input which consists of point-to-point values calculated for each $1 \mathrm{~ms}$ sampling time was produced. Meanwhile, the PID position control tuned by trial and error and Ziegler Nichols (Z-N) methods were carried out and measured for comparison in terms of steady state error, overshoot and response time in real-time experiments. It could be observed that step input has caused abrupt movements and vibration to the arm body compared to the parabolic input that moved the arm smoothly to imitate motion like human. Meanwhile, the intuitive values of trial and error method were found to produce not much different with the $Z-N$ tuned gains but comparatively produced small error against the parabolic input reference during the transient state. The result from this study is useful in the future to ensure position accuracy of robot joints when attending object for manipulation.
\end{abstract}

Keywords : Heuristic PID tuning, trial and error tuning method, Ziegler-Nichols, robot arm control.

\section{INTRODUCTION}

The development of robots has been applied widely in various applications such as industry, health care and services. Robots are moving into embracing human-like motion and control that fits the capability for work. This attracted interest in researchers to explore robot technology which includes areas such as hardware design and instrumentation, control, interface and sensors.

PID is the typical type of controller that is still widely used to control the performance of robots due to several aspects. It has the capability to reduce noise, disturbances and friction that occur in a plant or process [1]-[3] based on simple algorithm. Reference [3] has made an in depth overview on

Revised Manuscript Received on July 22, 2019.

* Correspondence Author

M. F. M. Ariffin, Faculty of Electrical Engineering, Universiti Teknologi MARA, 40450, Shah Alam, Selangor, Malaysia.

R. L. A. Shauri*, Faculty of Electrical Engineering, Universiti Teknologi MARA, 40450, Shah Alam, Selangor, Malaysia. Email: ruhizan@uitm.edu.my

M. I. Roslan, Faculty of Electrical Engineering, Universiti Teknologi MARA, 40450, Shah Alam, Selangor, Malaysia.

W. M. L. W. Zainudin, Faculty of Electrical Engineering, Universiti Teknologi MARA, 40450, Shah Alam, Selangor, Malaysia.

M. A. Rosli, Faculty of Electrical Engineering, Universiti Teknologi MARA, 40450, Shah Alam, Selangor, Malaysia. mathematical equation of PID in terms of control and PID technology packages that were used by the industries. Existing PID tuning methods such as analytical, optimization, heuristic, frequency response and adaptive methods have been explained briefly.

Shahroki and Zomorrodi compared several PID tuning methods which include closed loop and open loop Ziegler-Nichols (Z-N), Tyreus-Luyben, damped oscillation and Cohen-Coon methods through simulation test of a known system's dynamics with dead time [4]. The authors concluded that the closed loop Z-N has comparatively outperformed other methods in the measurement of integral absolute error index in two cases i.e. set point tracking and load rejection tests. Similar comparison study in [5] has compared between Z-N method, Chien-Hrones-Reswick method and Cohen-Coon method for PID precision positioning control of a single axis of an XY stage 3D surface profiler. The study has observed Cohen-Coon as the best method for minimizing the positioning error.

Reference [6] has tested several tuning methods from optimization techniques which consists of among others Bat Algorithm, Genetic Algorithm (GA) and Bee Swarm, to the conventional methods such as Cohen-Coon, Hallman and internal model control (IMC). The simulation results for a system modelled by system identification method were compared with the result from experiment where the optimization technique was observed to perform better than the conventional method. On the other hand, modern control methods are also gaining attention where model equation of plant or process is embedded within complicated control algorithms. This includes study by [7] where comparison for the performance of a brushless motor position control in simulation tests using model reference adaptive control (MRAC) and Fuzzy PID has shown that the former has performed better. Another study [8] has used Particle Swarm Optimization (PSO) technique and Bacterial Foraging (BF) technique to obtain the optimal gains of PID to control the speed of a brushless motor. From the simulation results, PSO is found to outperform BF in obtaining the PID gains for the control.

In robotic related studies, modern type controllers have been explored and developed where some combines with or modifies the classical PID controller to achieve robot's accuracy and practicality for work. Kazemian has compared the control performance of his proposed self-organizing Fuzzy-PID (SOF-PID) controller [9] with a self-organizing fuzzy (SOFC) [10] and PID controllers. The integral and derivative gains of SOF-PID were tuned by Z-N and capable of being calculated during system operation.

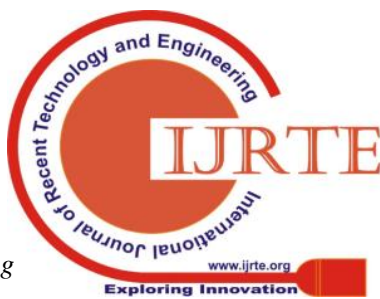




\section{Two Heuristic PID Tuning for a 4-DOF Robot Arm Control}

SOF-PID has been proven to outperform the other two for the position control of a MIMO nonlinear robot arm joints in tracking an assigned set of point references.

Meanwhile, study in [11] has applied a Fuzzy PID controller for angle tracking control of a rehabilitation robotic hand which consists of a pneumatic actuation and pulley mechanism. Their work concluded that their Fuzzy PID controller proved to give better performance than using fixed gains of conventional PID controller. In other work, Linear Matrix Inequalities (LMI) was applied to solve the vibration and control of a flexible robot arm namely Service-Arm Type CS-113 robot [12]. The state-feedback fuzzy controller was designed based on neuro-fuzzy state-space model of the arm which was found to outperform the previous PI and strain controller in experiment. Meanwhile, Fuzzy PID controller with gains tuned by GA method was introduced by [13] to solve difficult coupling and nonlinearity problem of their robot arm. Salleh et al. established a Fuzzy PID control tuned by experience from several experimental results for their three-fingered robot hand and proved that the proposed method outperformed a conventional PID controller towards compensating disturbance in a range of different payloads of the hand [14].

This paper discusses the development of PID controller for a four degree of freedom (4-DOF) robotic arm. Two tuning methods were applied to obtain the PID gains and compared in terms of steady state error, percentage overshoot and the response time. A PC is used as the host computer for the control system with encoders to measure the motor position. The closed loop position control of the four motor joints was programmed in MATLAB Simulink which allows offline and real-time online tests to be observed by user for analysis.

\section{4-DOF ROBOT ARM SYSTEM}

\section{A. Arm Design and System}

In the previous work, the structure, hardware and control interface of the prototype robot arm were constructed with the objective of developing an arm for a robotic hand to implement task in 3D workspace. The hand developed in previous studies have three fingers for object grasping [15] and applied position and force control in its execution $[16,17]$. Meanwhile, the arm consists of four revolute joints actuated by DC motors and encoders as sensors [18]. The control is programmed on MATLAB Simulink Real-time Workshop with fixed angle positions as reference to move all joints in real time. Table- I and Fig. 1 show the design and robot's specifications, respectively.

Table- I: Robot Specifications

\begin{tabular}{|l|l|}
\hline Parameter & Specification \\
\hline Control & PID control on MATLAB Simulink \\
\hline DOF & 4 Links \\
\hline Sensor & Magnetic Encoder \\
\hline Interface & $\begin{array}{l}\text { Arduino Mega 2560 } \\
\text { (4 PWM and 16 Digital Input Output) }\end{array}$ \\
\hline Sampling Time & 1ms \\
\hline Pulse Motor & $\begin{array}{l}\text { Motor 1 and 2: 520 pulse/rotation } \\
\text { Motor 3 and 4: 700 pulse/rotation }\end{array}$ \\
\hline Types of Motor & IG42E - 104K and IG32E - 100K \\
\hline
\end{tabular}
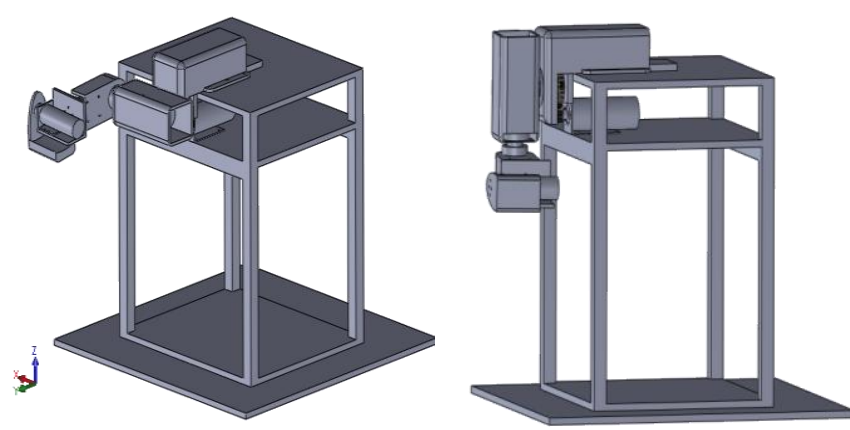

(a) Arm attached to base platform

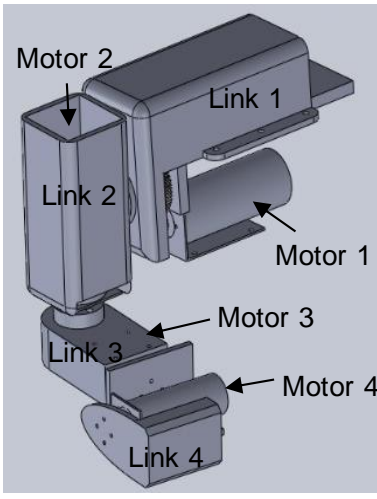

(b) Arm design

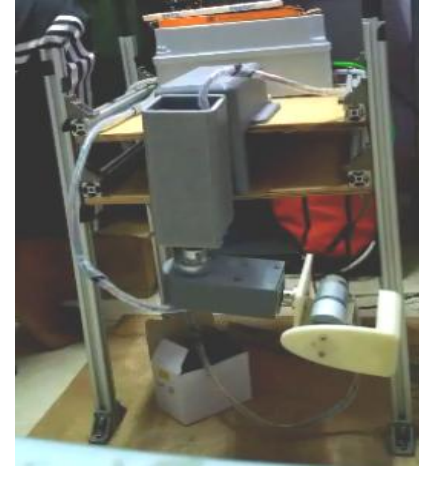

(c) Fabricated arm
Fig. 1. Prototype 4-DOF robot arm

\section{B. PID Control and Applied Tuning Methods}

The basic closed-loop feedback control is constructed based on the block diagram in Fig. 2. PID controller requires a set of predetermined values of its $\mathrm{P}, \mathrm{I}$ and $\mathrm{D}$ gains as shown in the Simulink block programming in Fig. 3 where they are the proportional, integral and derivative of the input error signal of the motor position. Therefore, heuristic tuning techniques such as trial and error and Ziegler-Nichols methods were used since both do not require the model equation of the system.

Tuning of the PID control gain was implemented to obtain the desired performance of the control to achieve zero percentage overshoot and steady state error, and the shortest possible response time.

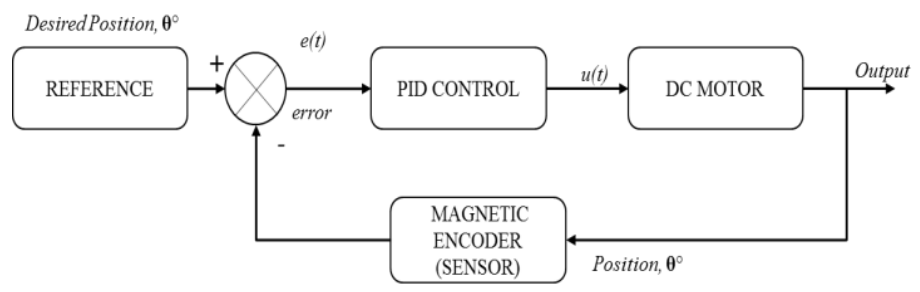

Fig. 2. Closed-loop control system block diagram 


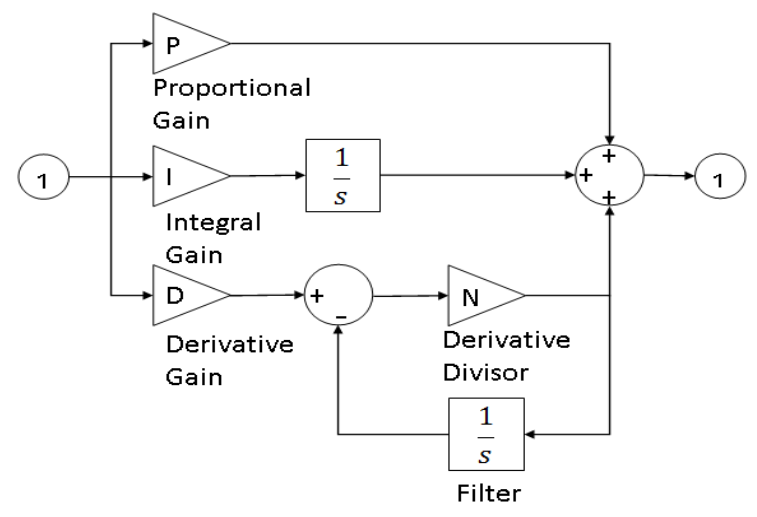

Fig. 3. Basic components of PID Controller

In trial and error tuning method, the steps start by setting the derivative $K_{d}$ and integral $K_{i}$ gains to zero while increasing the proportional gain $\mathrm{K}_{\mathrm{p}}$ gradually until the response of the system produces consistent oscillation at the desired position. Once done, the tuning proceeds to the integral and derivative terms.

Similarly, with Ziegler-Nichols method II [4], [19], $\mathrm{K}_{\mathrm{d}}$ and $\mathrm{K}_{\mathrm{i}}$ are also first set to zero while $\mathrm{K}_{\mathrm{p}}$ is increased with the same manner. From the result, the critical value $\mathrm{P}_{\text {crit }}$ is identified as the time taken between two peaks of the oscillation as illustrated in Fig. 4. $\mathrm{P}_{\text {crit }}$ is then used to calculate the integral and derivative gains using the formula written in the third row of Table- II for PID controller. The Ziegler-Nichols tuning method took less time to obtain the gains since it requires the tuning for only the proportional gain to obtain the constant oscillation.

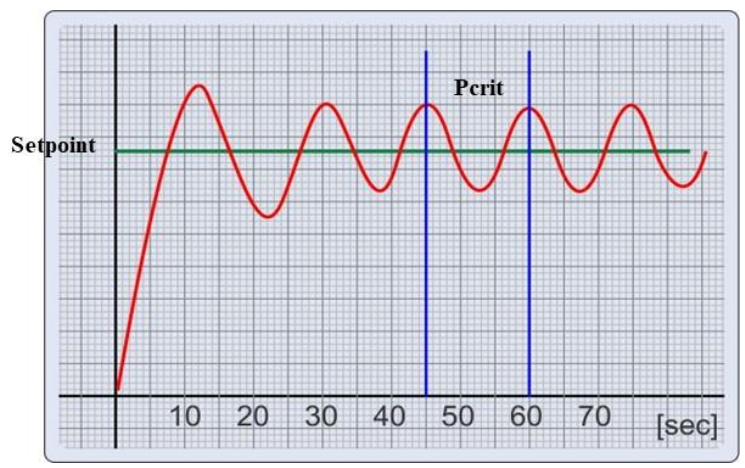

Fig. 4. Sustain oscillation of critical gain

Table- II: Ziegler-Nichols Method 2 tuning chart

\begin{tabular}{|c|c|c|c|}
\hline $\begin{array}{c}\text { Gains/ } \\
\text { Controller }\end{array}$ & $\mathrm{Kp}$ & $\mathrm{Ki}$ & $\mathrm{Kd}$ \\
\hline $\mathrm{P}$ & $0.5 \mathrm{Kcrit}$ & $\infty$ & 0 \\
\hline $\mathrm{PI}$ & $0.45 \mathrm{Kcrit}$ & $(1 / 1.2) *$ Pcrit & 0 \\
\hline PID & 0.6 Kcrit & $0.5 *$ Pcrit & $0.125 *$ Pcrit \\
\hline
\end{tabular}

\section{A. Real-Time Experiment}

The PID control of the arm was tested in real time by introducing reference inputs to each motor. Motor 1 and 2 were directed from $0^{\circ}$ to the $90^{\circ}$ while motor 3 and 4 were directed from $0^{\circ}$ to $180^{\circ}$. Meanwhile, for Z-N, motor 1 and motor 2 were directed from $0^{\circ}$ to $270^{\circ}$ and $90^{\circ}$, respectively, while motor 3 and 4 were directed from $0^{\circ}$ to $45^{\circ}$. Graphs of the reference position compared to the actual motor position measured by encoders were used to observe the control parameters performance.

\section{RESULTS AND DISCUSSION}

Graphs in this section are presented with horizontal axis that represents the time (in ms) and vertical axis as the position of the motor (in degree). The blue lines in Fig. 5 shows the generated parabolic curve signal using mathematical spline interpolation method as the input reference. The red lines are not giving any reading because the encoders were not connected to the interface in this offline test. Fig. 5(c) shows the trajectory generated by this signal for all joint motors.

Fig. 6 shows the results of the output response using the tuned PID gains by trial and error method while Fig. 7 shows the results using Z-N method. The blue and the red lines in Fig. 6 and 7 represent the desired position and actual position (or named as actual/current positon in graph), respectively. Gains applied for motor 1, 2, 3 and 4 are shown in the respective graphs.

Fig. 6 consists of the output response of motor 1 to motor 4 arranged from top to bottom. It can be observed that the actual response clearly followed the reference value very well to achieve zero overshoot, zero steady state error and no jitters on the signal at the steady state. However, for motor 1 and 2 as shown in Fig. 6(a) and (b), small error occurred at the beginning of the control at time around $50 \mathrm{~ms}$ before it successfully tracked back the desired reference and return to initial $0^{\circ}$ position. Meanwhile, as shown in Fig. 7, Z-N method has also achieved zero overshoot, zero steady state error and no jitters on the signal.

These results show that both tuning methods can practically work for the position control despite of nonlinearities from gear/bearing/shaft frictions and the unknown model of the system. However, Z-N proved to be better in producing consistent output response to follow the desired trajectory at all time.

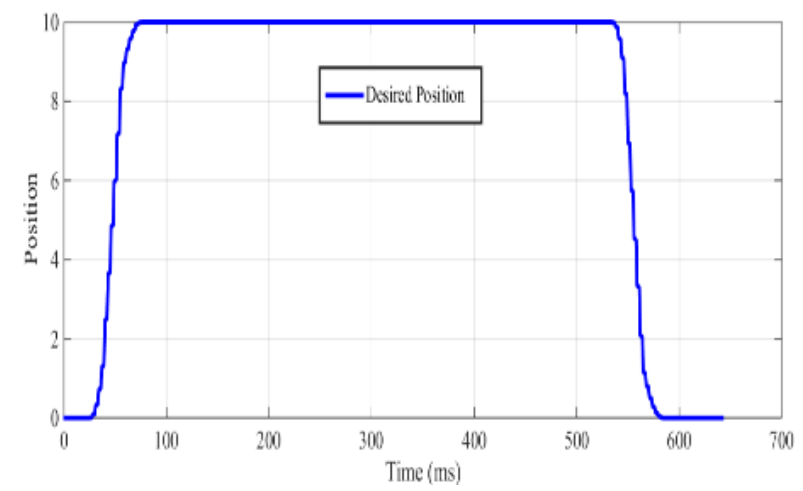

(a) Motor 1 
Two Heuristic PID Tuning for a 4-DOF Robot Arm Control

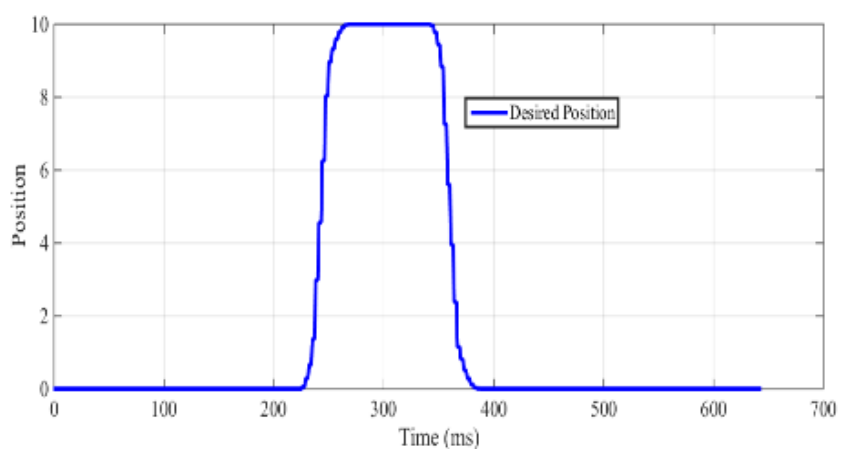

(b) Motor 4

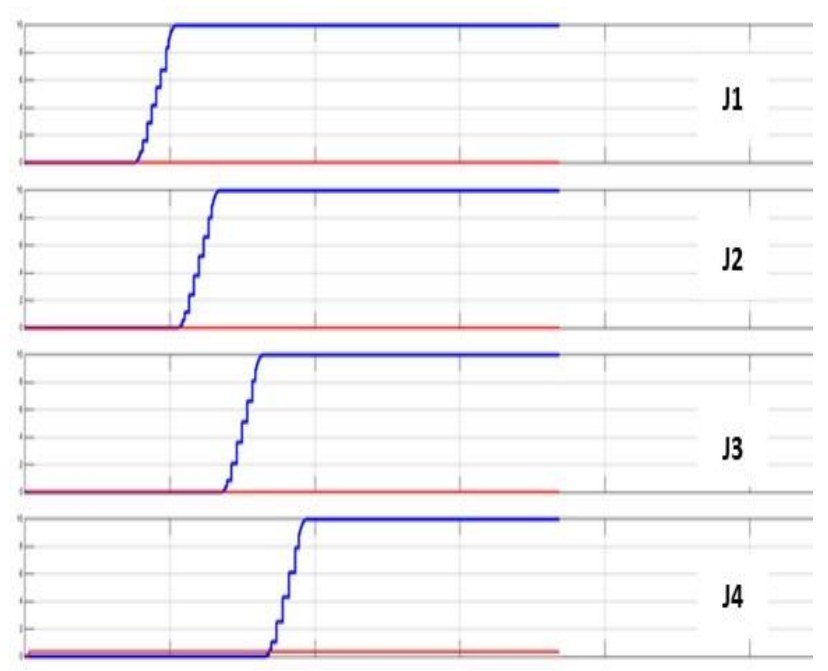

(c) All joint motors (J1 4 represent motor 1 4)

Fig. 5: Simulation of parabolic reference

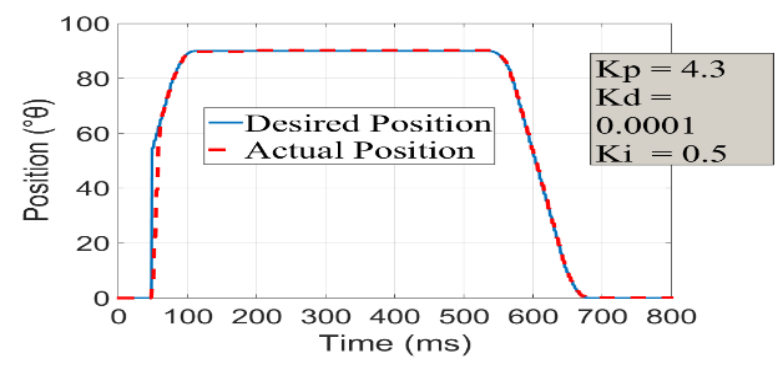

(a) Motor 1

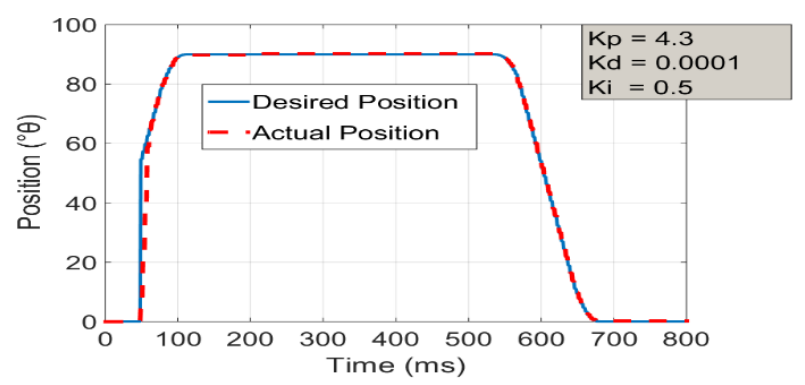

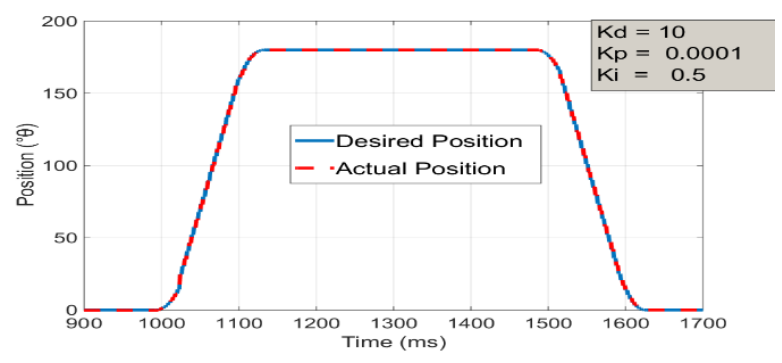

(c) Motor 3

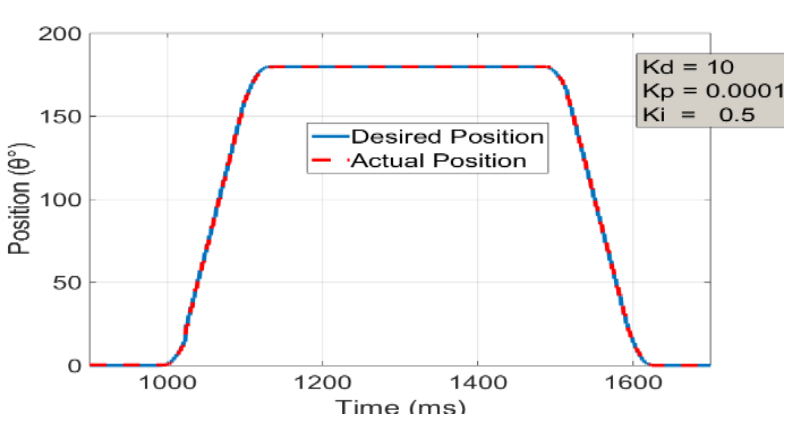

(d) Motor 4

Fig. 6. Position control by trial and error tuning method

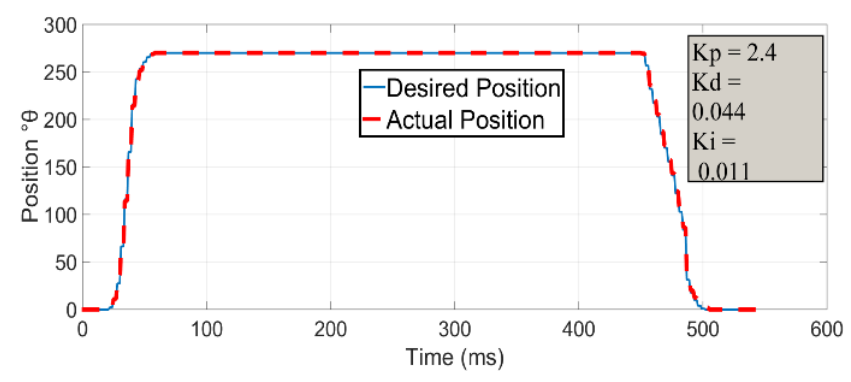

(a) Motor 1 


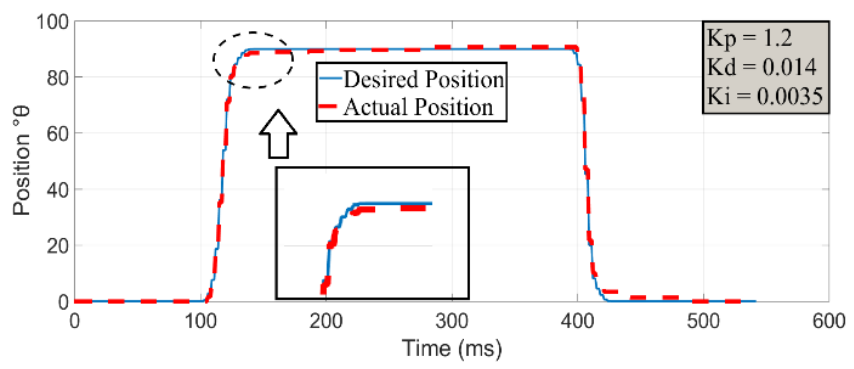

(b) Motor 2

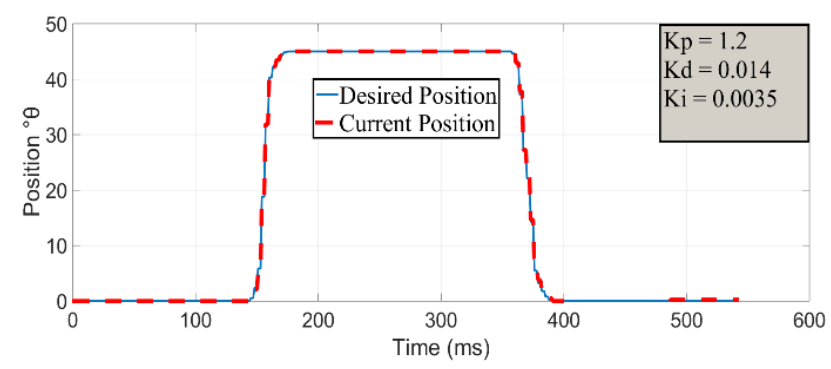

(c) Motor 3

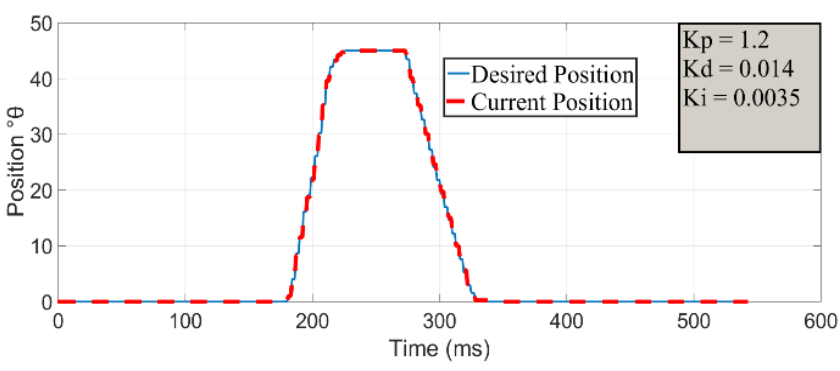

(d) Motor 4

Fig. 7. Position control using by Z-N tuning method

\section{CONCLUSION}

A parabolic curve which consists of point-to-point values in $1 \mathrm{~ms}$ intervals was successfully produced and used as reference input to the 4-DOF arm robot control system programmed on MATLAB Simulink. PID control tuned by trial and error and Ziegler Nichols (Z-N) methods were carried out and measured for comparison in real-time experiments. The control performance by trial and error method was found to be not much different with the Z-N but comparatively produced small error against reference during the transient state. The output response of $\mathrm{Z}-\mathrm{N}$ method proved to be more consistent in tracking the desired trajectory at all time. It can be concluded that both tuning methods can practically work for the position control of the robot joints despite of the nonlinearities from the gear/bearing/shaft frictions and unknown model of the system. The result from this study is useful in the future to acquire position accuracy of the robot joints when attending object for manipulation.

\section{ACKNOWLEDGMENT}

This research was supported by Research Management
Centre (RMC) and Faculty of Electrical Engineering, Universiti Teknologi MARA, Malaysia through LESTARI Grant (600-IRMI/MyRA 5/3/LESTARI (080/2017)).

\section{REFERENCES}

1. Norman S.Nise, Control System Engineering, 4th Edition. United States of America: John Wiley \& sons, 2004, pp. 983.

2. K. H. Ang, G. Chong and Y. Li, "PID Control System Analysis, Design, and Technology," IEEE Transactions on Control Systems Technology, vol. 13, no. 4, pp. 559-576, 2005.

3. B. D. Sellers, "An Overview of Proportional plus Integral plus Derivative Control and Suggestions for Its Successful Application and Implementation," 2001 First International Conference for Enhanced Building Operations, 2001.

4. M. Shahrokhi and A. Zomorrodi, Comparison of PID controller tuning methods.

Available:

https://www.semanticscholar.org/paper/1-Comparison-of-PID-Controll er-Tuning-Methods-Shahrokhi-Zomorrodi/116ce07bcb202562606884c 853fd1d19169a0b16, Accessed on 17 ${ }^{\text {th }}$ April, 2018.

5. R. Sen, C. Pati, S. Dutta S. and R. Sen, "Comparison Between Three Tuning Methods of PID Control for High Precision Positioning Stage," MAPAN-Journal of Metrology Society of India, vol. 30, no. 1, pp 65-70, 2015.

6. J. M. S. Ribeiro, M. F. Santos, M. J. Carmo and M. F. Silva, "Comparison of PID controller tuning methods: analytical/classical techniques versus optimization algorithms," 18th International Carpathian Control Conference (ICCC), Sinaia, pp. 533-538, 2017.

7. Adel A. El-samahy, Mohamed A. Shamseldin, "Brushless DC motor tracking control using self-tuning fuzzy PID control and model reference adaptive control," Ain Shams Engineering Journal, vol. 9, issue 3, pp. 341-352, 2018.

8. H.E.A. Ibrahim, F.N. Hassan, Anas O. Shomer, "Optimal PID control of a brushless DC motor using PSO and BF techniques," Ain Shams Engineering Journal, vol. 5, issue 2, pp. 391-398, 2014.

9. H. B. Kazemian, "The SOF-PID controller for the control of a MIMO robot arm," IEEE Transactions on Fuzzy Systems, vol. 10, no. 4, pp. 523-532, Aug 2002

10. E. H. Mamdani and N. Baaklini, "Prescriptive method for deriving control policy in a fuzzy logic controller," Electron. Lett., vol. 1, pp.625-626, 1975.

11. J. Wu, J. Huang, Y. Wang, K. Xing, and Q. Xu, "Fuzzy PID control of a wearable rehabilitation robotic hand driven by pneumatic muscles," 2009 Int. Symp. Micro-NanoMechatronics Hum. Sci., pp. 408-413, 2009.

12. A. Chatterjee, R. Chatterjee, F. Matsuno and T. Endo, "Augmented Stable Fuzzy Control for Flexible Robotic Arm Using LMI Approach and Neuro-Fuzzy State Space Modeling," IEEE Transactions on Industrial Electronics, vol. 55, no. 3, pp. 1256-1270, March 2008.

13. J. Zhao, L. Han, L. Wang and Z. Yu, "The fuzzy PID control optimized by genetic algorithm for trajectory tracking of robot arm," 2016 12th World Congress on Intelligent Control and Automation (WCICA), Guilin,pp. 556-559, 2016.

14. Salleh, N. M., Shauri, R.L.A., Nasir, K., Remeli, N. H., "Fuzzy-PID position control for grasping by Three-Fingered Robot Hand," Journa of Mechanical Engineering, vol. SI 4 (1), pp. 61-77, 2017.

15. J. Jaafar and R. L. A. Shauri, "Three-fingered robot hand for assembly works," 2013 IEEE 3rd International Conference on System Engineering and Technology (ICSET), Shah Alam, pp. 237-241, 2013.

16. Shauri, R.L.A., Salleh, N.M., Hadi, A.K.A., "PID position control of 7-DOF three-fingered robotic hand for grasping task," 4th IEEE International Conference on Control System, Computing and Engineering (ICCSCE), pp. 70-74, 2014.

17. Nasir, K., Shauri, R.L.A., Salleh, N. M., Remeli, N. H., "Implementation of Two-Axis Position-Based Impedance Control with Inverse Kinematics Solution for A 2-DOF Robotic Finger," International Journal of Engineering \& Technology, vol. 7, no. 3.11, pp. 10-14, 2018

18. Mustaffa, M.F., Shauri, R.L.A., Roslan, M.I., Idris, M.A., "Development of a 4-DOF Robotic Arm: Prototype Design," International Journal of Engineering \& Technology, vol. 7, no. 4.18, pp. 429-432, 2018.

19. P. Parikh, R. Vasani and S. Sheth, "Velocity Analysis of a DC Brushed Encoder Motor using Ziegler-Nichols Algorithm: A Case of an Automated Guided Vehicle," Indian Journal of Science \& Technology, vol. 9 , no. 38,2016 


\section{AUTHORS PROFILE}

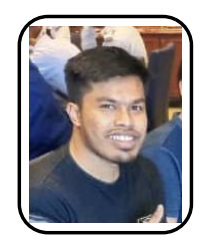

M. F. M. Ariffin will be graduating with B.Eng. in Electrical Engineering from Universiti Teknologi MARA, Malaysia in 2019. He has worked with the research group since 2018 until early 2019 focusing on improving the control of the robot joints.

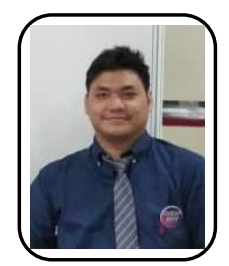

M. I. Roslan received his B.Eng. in Electrical Engineering from Universiti Teknologi MARA, Malaysia in 2019. He has worked with the research group since 2017 until 2018 focusing on improving the control of the robot joints.

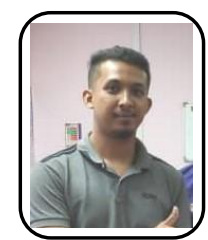

W. M. L. W. Zainudin will be graduating with B.Eng. in Electrical Engineering from Universiti Teknologi MARA, Malaysia in 2019. He has worked with the research group since 2018 until early 2019 focusing on improving the interface system for the robot control.

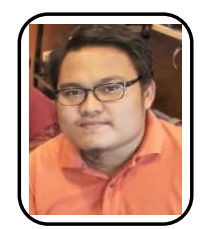

M. A. Rosli will be graduating with B.Eng. in Electrical Engineering from Universiti Teknologi MARA, Malaysia in 2019. He has worked with the research group since 2018 until early 2019 focusing on the robot design.

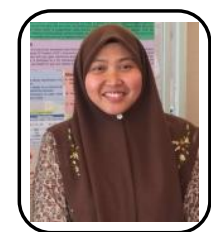

R. L. A. Shauri received her B.Eng. in Electrical Engineering from University of Hiroshima, Japan in 1999, M.Sc. degree in Control and Automation from Universiti Putra Malaysia, Malaysia in 2006, and Ph.D. degree in Artificial Systems Science from University of Chiba, Japan in 2012. From 1999 to 2002, she was a Design Engineer with Sumitomo Globetronics Sdn. Bhd., Penang, Malaysia. Currently working as assistant professor at the Faculty of Electrical Engineering, Universiti Teknologi MARA, Malaysia. Her current research interests include robot design and control, and image processing methods for robotic application. To date she has produced $3 \mathrm{MSc}$. graduates and 30 publications related to these areas. 